educational and activity projects to improve cooperation and help children to understand and respect others. ${ }^{1}$ This encourages children to feel involved, and grow as responsible adults.

As a volunteer I got the opportunity to attend some weekend camps. Here I had to improvise games, make toys, and join the children in play to kindle their enthusiasm, before they could accept me as their peer. Once accepted, they discussed their personal problems and worries.

In one of the camps, I noticed a girl aged 12, who was withdrawn, and not actively participating in games. When she got to know me better, she confessed that 'her walk was funny', and so wanted to avoid any one noticing it. I could not see any abnormal gait, but understood that she had developed a complex. Her father had always mocked her walking. After a long discussion, and involving her friends, we restored her confidence. Similarly children who had concealed their asthma medication, coughed all night. Once I got to know about this, I helped them to understand their illness, and they took their medication regularly. These informal discussions with children helped me to understand their problems, and improved my communication with them.

I feel that every doctor or a nurse who is working with children should seek similar opportunities, and attend camps to educate themselves, and learn the art of communicating and understanding their young clients better. Encouraging this type of activity helps children learn to cooperate with others, and live in harmony as well behaved youngsters. This may help us to keep youngsters off the streets, and also decrease their antisocial activities in the community. Department of Paediatrics, Hospital, Aylesbury, Bucks HP21 $8 A L$

1 The Woodcraft Folk. Annual report. London: The Woodcraft Folk, 1995.

\section{Cardiac effects of growth hormone in} short normal children

EDITOR,-In our recent article the formula for body surface area was stated incorrectly. ${ }^{1}$ It should read body surface area $=$ weight $^{0.425} \times$ height $^{0.725} \times 0.007184$ (height in $\mathrm{cm}$, weight in $\mathrm{kg}$ ). ${ }^{2}$ The relative merits of formulas versus nomograms have been previously underlined. ${ }^{3}$ Such formulas are rarely seen in print and it is therefore important for safe practice for them to be correctly documented. The calculations, however, were all based on the correct formula.

$$
\begin{array}{r}
\text { PIERS E F DAUBENEY } \\
\text { PETER R BETTS } \\
\text { STEVEN A WEBBER } \\
\text { Wessex Cardiothoracic Centre and Department of } \\
\text { Paediatrics, } \\
\text { Southampton General Hospital, } \\
\text { Southampton SO16 6YD }
\end{array}
$$

1 Daubeney PEF, McCaughey EM, Chase C, Slavik Z, Betts P, Webber SA. Cardiac effects of growth hormone in short normal children: results after 4 years of treatment. Arch Dis Child 1995; 72: 337-9.

2 DuBois D, DuBois EF. Clinical calorimetry: X. A formula to estimate the approximate surface area if height and weight be known. Arch Intern Med 1916; 17: 863-71.

3 Briars GL, Bailey BJR. Surface area estimation: pocket calculator $v$ nomogram. Arch Dis Child 1994; 70: 246-7.

\section{BOOK REVIEWS}

Surgical Emergencies in Children. A Practical Guide. Edited by P A M Raine and A A F Azmy. (Pp 355; $£ 65$ hardback.) Butterworth Heinemann, 1994. ISBN 07506-1389-0.

This new publication covers a range of surgical emergencies affecting children and gives some background to the surgical conditions and concentrates on first line management and investigation. It tackles subjects by clinical presentation rather than pathology and is aimed at the non-paediatric surgical specialty trainee, casualty, and nursing staff. It covers a wide range of presenting symptoms, though by nature of the book, many rather superficially.

This topic has been poorly covered by recent texts, the majority of which have been major in-depth texts, unsuitable for quick reference by non-specialist staff. It is well laid out with short paragraphs, an easily readable concise style, bullet lists, and subtitles.

It is a shame that in the first chapter on emergency surgical admission, there is no stress on basic resuscitation, neither do APLS (ATLS) techniques appear here nor as a preface to a general trauma section. The illustrations are well chosen and helpful, though a few more examples of practical procedures would be useful, such as suprapubic aspiration and reduction of hernia. It would also be useful to have covered the role of the regional and supraregional specialist unit and transfer of the sick child, in particular neonates. The authors have set out to cover a large subject in an easily accessible format. The cost of this to some extent has been to lose any impression of the multiple controversies that exist within paediatric surgery. In picking a simple treatment plan, there are management suggestions that would not be acceptable in other centres in the UK, for example, that it is ever preferable to perform a pyloromyotomy under local anaesthesia or that it should ever, with careful management of the underlying electrolyte including potassium deficiency, be impossible to correct the electrolyte imbalance.

In general I feel the book is well written, well presented, with good illustrations. It will form a much needed up-to-date source of reference for medical students, nursing staff, and junior hospital doctors in the nonspecialist environment.

ROWENA HITCHCOCK Senior registrar in paediatric urology

Photosensitive Epilepsy. By Graham F A Harding and Peter $M$ Jeavons. (Pp 182; $£ 27.95$ hardback.) Cambridge University Press, 1995. ISBN 1-898-68302-6.

As a newly appointed consultant, I was perplexed and challenged by Scott, a severely handicapped little boy who would be brought into the consulting room and promptly have a seizure on staring at the tartan squares on the carpet. If his mother could distract him from the carpet, his gaze would seek the linear patterns in the curtains, or worst still my striped blouse, and further absence attacks would occur. Neither the books nor my more erudite colleagues could help much but his mother was convinced that he was sensitive to patterns.

The new edition of Photosensitive Epilepsy sheds much light on the phenomenon of pattern sensitivity and tells us far more besides about photosensitive epilepsy. The text is based on the authors' study of the largest cohort of photosensitive patients ever achieved (now over a 30 year period) and details new diagnostic techniques, prognosis, and genetic implications of the condition.

The authors strongly argue that attention to correct EEG technique is essential to demonstrate photosensitivity reliably. A photoconvulsive response is often familial, is twice as common in females, and presents typically around puberty (although the history often suggests it may have been present for some years before it is recognised). Long term follow up studies indicate that a quarter of patients lose their photosensitivity with age.

In western Europe the commonest precipitant of photosensitive epilepsy is television viewing (due to $A C$ mains supply which alternates at $50 \mathrm{~Hz}$ ). In 1993, 'videogame' epilepsy was given much footage in the European press as increasing numbers of seizures were reported in children who watched videos. Most video monitors are $70 \mathrm{~Hz}$ (and thus likely to be outside the photosensitivity range) and many children seized as a result of playing with hand held modules or in game arcades. Thus, there was an additional factor other than simple photosensitivity. The authors were in the vanguard of opinion that this was likely to be pattern sensitivity and they discuss their evidence for this.

The fascinating subject of self induced photosensitive epilepsy is considered in which children have a compulsive attraction for TV (sometimes being drawn across a road to watch TV in shop windows). If they can get close enough to the set, they will have a seizure. Self induced pattern epilepsy is much rarer and is usually found in children with learning disability.

There is a chapter on treatment and, although avoidance of stimuli is still recommended, there has been a change of view regarding drug treatment. It is now recommended that all young people with primary photosensitive epilepsy are treated with sodium valproate because of the increasing exposure to provocative visual stimuli in modern day life. The book contains a large number of useful and fascinating facts, including pattern testing techniques and the stringent testing techniques applied to pilots, divers, and train drivers.

I would consider the book essential reading for all doctors who treat patients with epilepsy.

GAYNOR F COLE Consultant paediatric neurologist

Recent Advances in Paediatrics - 13 Edited by T J David. (Pp 233; $£ 26.50$ paperback.) Churchill Livingstone, 1994. ISBN 0443-05100-3.

'When I was a boy: World a better spot What was so was so: What was not was not'

There are different approaches to the problem of keeping up to date. The least effective is that of the ostrich, stick your head in the sand 